\title{
Gut Luminal and Clinical Benefits of Early Enteral Nutrition in Shock
}

\author{
Mark Barash $^{1} \cdot$ Jayshil J. Patel $^{2}$
}

Published online: 29 August 2019

(C) Springer Science+Business Media, LLC, part of Springer Nature 2019

\begin{abstract}
Purpose of Review Circulatory shock and subsequent gut hypoperfusion turn on the 'gut motor,' which impairs gut barrier function, promotes dysbiosis, and generates immune dysfunction to perpetuate inflammation. Clinicians may be reluctant to commence enteral nutrition in circulatory shock out of concern for bowel ischemia and splanchnic steal syndrome. Here, we identify contemporary studies which have evaluated the impact of enteral nutrition during circulatory shock on gut lumen functions and clinical outcomes.

Recent Findings Recent studies show enteral nutrition has luminal benefits and is safe. Observational and pilot randomized controlled trial data evaluating early enteral nutrition in circulatory shock suggest an association between early enteral nutrition and improved clinical outcomes.

Summary Contemporary literature suggests enteral nutrition continues to have gut lumen benefits and is associated with improved clinical outcomes. Future trials are needed to evaluate optimal dose, timing, and composition of enteral nutrition in circulatory shock.
\end{abstract}

This article is part of the Topical collection on Nutrition, Metabolism, and Surgery.

Jayshil J. Patel

jpatel2@mcw.edu

1 Division of Pulmonary \& Critical Care Medicine, Department of Medicine, Medical College of Wisconsin, Milwaukee, WI, USA

2 Division of Pulmonary \& Critical Care Medicine, Medical College of Wisconsin, 8701 West Watertown Plank Road, HUB, 8th Floor, Milwaukee, WI 53226, USA
Keywords Enteral nutrition $\cdot$ Shock $\cdot$ Sepsis $\cdot$ Septic shock $\cdot$ Microbiome · Gut microbiota

$\begin{array}{ll}\text { Abbreviations } \\ \text { ARDS } & \text { Acute respiratory distress syndrome } \\ \text { B/F } & \text { Bacteroidetes/firmicutes ratio } \\ \text { EN } & \text { Enteral nutrition } \\ \text { IEC } & \text { Intestinal epithelial cell } \\ \text { IFN- } \gamma & \text { Interferon gamma } \\ \text { I-BABP } & \text { Ileal bile-acid binding protein } \\ \text { I-FABP } & \text { Serum intestinal fatty acid binding protein } \\ \text { Muc2 } & \text { Mucin 2 } \\ \text { NOBN } & \text { Non-occlusive bowel necrosis } \\ \text { NOMI } & \text { Non-occlusive mesenteric ischemia } \\ \text { PN } & \text { Parenteral nutrition } \\ \text { RCT } & \text { Randomized controlled trial } \\ \text { SCFA } & \text { Short-chain fatty acid } \\ \text { sp } & \text { Species } \\ \text { TJ } & \text { Tight junction } \\ \text { TLR4 } & \text { Toll-like receptor } 4 \\ \text { TNF- } \alpha & \text { Tumor necrosis factor alpha } \\ \text { VA-ECMO } & \text { Veno-arterial extracorporeal membrane } \\ & \text { oxygenation } \\ \text { ZO } & \text { Zona occluden }\end{array}$

\section{Introduction}

In 1942, Cuthbertson described the 'ebb' and 'flow' phases of critical illness [1]. An early hyperacute phase of hemodynamic instability hallmarks the 'ebb' phase where critically ill patients are undergoing resuscitation and often require vasopressor support to maintain blood pressure and 
oxygen delivery [2]. The 'ebb' phase also represents a period of vulnerability for gut barrier and immune functions and microbiota composition. Historically, nutrition has been considered a form of support whereby it provides calories during catabolism, and increases mitochondrial function and protein synthesis to maintain lean body mass and enhance muscle function. Enteral nutrition (EN), as a form of therapy, has been shown to preserve intestinal barrier function, maintain immunity, and limit gut dysbiosis. In this narrative review, we describe gut dysfunctions observed in shock, their clinical consequences, identify recent literature evaluating luminal benefits of $\mathrm{EN}$ in shock, and identify recent literature examining the safety and clinical benefits of EN in shock.

\section{The Consequences of Circulatory Shock on Gut Barrier and Immune Functions}

Circulatory shock leads to reduced oxygen delivery, often due to reduced effective circulating blood volume, and clinically manifesting as hypotension. As a result, widespread cellular and tissue hypoxia ensue. Early in shock, blood flow is diverted away from non-vital organs, such as the gut, to preferentially perfuse vital organs like the brain, heart, and kidneys.

Small intestine villous blood flows in opposite directions: arterial blood flows upwards towards the villus and venous blood flows towards the base [3]. Oxygen is extracted as blood moves towards the villus [3]. Since shock states shunt blood away from (non-vital) splanchnic circulation, the reduced splanchnic blood flow diminishes oxygen delivered to the villus tip, leaving it susceptible to ischemia. Furthermore, critical illness pathophysiology and processes accelerate enterocyte apoptosis and impair mucosal integrity, resulting in breakdown of barrier defense. As a result, toxic mediators are transported into the systemic circulation through lymphatic channels and create downstream organ dysfunction like acute respiratory distress syndrome (ARDS) [4•].

In health, tight junctions (TJ) link enterocytes and are selectively permeable to prevent the unregulated passage of intraluminal contents. Claudins, MARVEL domain proteins (occludin and tricellulin) and junctional adhesion molecules are common to all tight junctions. Zona occludens ( $\mathrm{ZO})$ proteins help link TJs to the cytoskeleton [5•]. Many components of the tight junction are altered in circulatory shock. Bacterial activation of myosin light chain kinase (MLCK) causes contraction of the actin-myosin ring and increases permeability at the cell-cell junction [6]. Systemic inflammation induced reduced expression of claudin or occludin proteins allow for bacterial adherence, which increases permeability [7•]. Furthermore, degree of
TJ disruption depends upon the severity of illness [8]. Higher serum TJ proteins and pro-inflammatory cytokines correlate to greater luminal TJ breakdown [9]. Vermette et al. reviewed 15 studies and concluded (a.) serum and urine levels of claudins-2,3 and 4 correlated with severity of acute gastrointestinal injury, (b.) serum ZO-1 best stratified sepsis severity and degree of organ dysfunction, and (c.) urinary claudins were a reliable measure of early gastrointestinal injury [5•].

Shock-associated gut barrier disruption modifies crosstalk between TJ proteins, gut bacteria and the immune system leading to immune dysregulation via influx, efflux and local perturbations of immune cells and inflammatory mediators. Innate lymphoid cells act to protect the gut barrier as early responders to pathogen invasion. CD4 $+\mathrm{T}$ cells are recruited and potentiate release of pro-inflammatory cytokines trending away from homeostasis [10]. Large-scale injury to intestinal epithelium facilitates an uncontrolled pathological immune response and organ dysfunction [11]. In a prospective observational study of 50 mechanically ventilated adults, delayed gastric emptying was associated with increased concentrations of inflammatory markers CD4 + $\alpha 4 \beta 7+$ CCR9 + T lymphocytes (known to preferentially migrate to the lamina propria of the small intestines). In the same study, patients had significantly higher serum concentrations of pro-inflammatory markers TNF- $\alpha$ and IL-1 $\beta$ and an increased intestinal barrier disruption was associated with higher serum intestinal fatty acid binding protein (I-FABP), ileal bileacid binding protein (I-BABP), and zonulin-1 [12]. Survivors of shock states may have long term elevations in inflammatory mediators which are predictive of higher mortality and worse outcomes [13].

\section{The Consequences of Circulatory Shock and Critical Illness on the Gut Microbiota}

Commensal organisms live in symbiosis with their host. The combination of commensal (nonvirulent) organisms, IgA, thick mucus layer, an acidic gastric environment, and peristalsis resist pathogenic bacterial colonization [14]. Critical illness pathophysiologic processes and clinical interventions (Table 1) alter the gut ecological system to (a.) increase microbial immigration, (b.) impair microbial clearance, and/or (c.) change environmental growth conditions. Gut hypoperfusion impairs mucosal integrity to increase bacterial and their product elimination through mesenteric lymphatics (alters microbial elimination) and increases mucosal inflammation (changes environmental growth condition) [14]. Clinical ICU interventions (or lack thereof), such as gastric acid suppression and diminished oral intake, further impair microbial elimination and 
promote acid-intolerant bacteria and create stress condition of nutrient scarcity, respectively. As a result, a healthy gut microbiota consisting of predominantly Firmicutes and Bacteroidetes is decimated and replaced by pathogenic Proteobacteria.

In the largest prospective observational study evaluating changes in the microbiome during critical illness, 115 mechanically ventilated critically ill adults had predominant Proteobacteria, consisting of gram negative rods, as compared to healthy controls from the American Gut Project, who had predominantly Firmicutes and Bacteroidetes $\left[15{ }^{\circ}\right]$. Severity of illness determines the degree of dysbiosis [14]. In 2017, Lankelma et al. found variation in the gut microbiota, predominated by Bacteroidetes and Proteobacteriae in critically ill septic patients, compared to predominant Firmicutes in healthy controls [16].

Exposure to the hospital setting alone has minimal effect on the upper respiratory tract bacterial community [14]. Rather, greater severity of illness induces more dysbiosis [14]. Bacteria thrive under stressful conditions like circulatory shock by changing their behavior, permitting them to subvert normal clearance mechanisms $[17,18 \bullet \cdot]$. Altered mucosal oxygen gradient and thinning of the intestinal mucosal layer that occur in circulatory shock favor Pseudomonas aeruginosa and Escherichia coli growth [14]. Babrowski et al. injected Pseudomonas into cecum of mice subjected to sham injury and then implanted the Pseudomonas into peritoneum of uninjured mice and all mice lived [19]. However, when Pseudomonas was injected into the cecum of mice subjected to $30 \%$ hepatotectomy (which induces inflammation) and then implanted into peritoneum of uninjured mice, all mice died. When exposed to stress (i.e., inflammation), Pseudomonas assumed a "wrinkled" pattern, effectively changing its behavior to become proinflammatory [19].

Dysbiosis has numerous consequences for the host. Virulent pathogens interact with epithelium, with or without invasion, and induce the release of mucosal-derived cytokines, which travel through mesenteric lymphatics to perpetuate inflammation and generate multiple organ dysfunctions. Gut-induced inflammation has been associated with more gastrointestinal complications, more organ dysfunction and infections, and greater mortality rate $[20,21]$. These interactions have been described as activation of the gut-lung or gut-lymph axis, for instance, and further our understanding of how local gut perturbations can have deleterious effects on distant organs.

Dickson et al. found similarities between gut and lung microbiota in both cecal ligation and puncture murine models and human subjects with ARDS, as compared to controls that had unique gut and lung microbial fingerprints [22]. Human specimens were dominated by Bacteroides

Table 1 Pathophysiologic (A) and ICU clinical interventions (B) and the mechanisms that alter the gut microbiota during critical illness

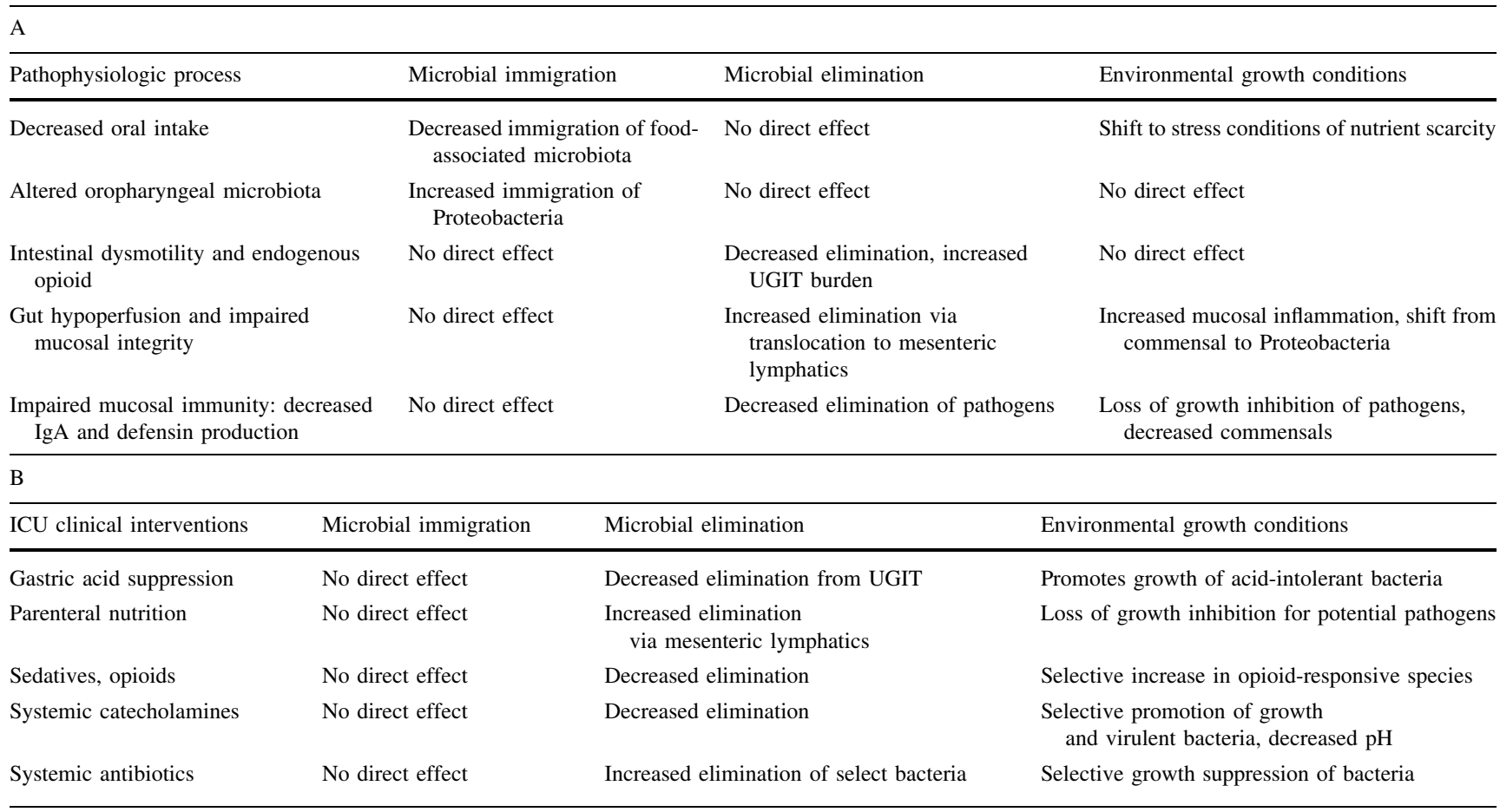

Adopted with permission from Reference [14]

IgA immunoglobulin A, UGIT upper gastrointestinal tract 
species (sp.) while murine models were dominated by Enterococcal sp. and Lachnospiraceae sp. The Bacteroides sp. proved to be culture negative but were identified using 16S ribosomal RNA sequencing techniques [22]. These observations support the need for novel techniques to identify pathogenic bacteria. Kojima et al. induced shock in a rat model and demonstrated exosome secretion into mesenteric lymph and further activation of lung macrophages via TLR4 that culminated in acute lung injury [23].

Since 2017, multiple studies have shown associations between gut dysbiosis and poor clinical outcomes [20, 24, 25]. Yamada et al. identified patients with systemic inflammatory response syndrome had a greater gut dysbiosis, which was associated with reduced fecal short-chain fatty acid concentration and more gastrointestinal complications [24]. Ojima et al. evaluated serial changes in gut microbiota in 12 critically ill patients and found an association between taxonomic composition and mortality. Four of six patients who died had a Bacteroidetes to Firmicutes ratio $>10$ and all survivors had a $\mathrm{B} / \mathrm{F}$ ratio $<10$ [25]. Lamarche et al. demonstrated loss of gut and lung biogeographical diversity in a prospective observational study of 34 mechanically ventilated ICU patients, which was associated with increased mortality [20]. The consequences of dysbiosis may last for weeks to months after resolution of critical illness [26].

\section{What are the Benefits of Early EN on Maintaining Luminal Defenses in Shock?}

The consequences of luminal underfeeding have been demonstrated with parenteral nutrition (PN) studies. During critical illness, PN is utilized exclusively when EN is not possible or as a supplement when calorie needs are not met by EN alone. Multiple contemporary RCTs have demonstrated feasibility and safety of delivering early exclusive PN [27]. However, exclusive PN has been associated with loss of intestinal barrier function [28], villous atrophy, increased intestinal epithelial cell (IEC) apoptosis, and decreased proliferation [29]. In murine models, Feng et al. demonstrated PN led to a decline in IEC proliferation and increased apoptosis [30]. PN dependent mice have increased levels of TNF- $\alpha$ and IFN- $\gamma$ [31] and toll-like receptor-4 (TLR4) levels [32]. In humans, Ralls et al. evaluated luminal nutrient deprived enterocytes in patients undergoing small bowel resection. They demonstrated loss of junctional integrity and marked increases in mucosal pro-inflammatory cytokines TNF- $\alpha$ and TLR4 [33].

At the luminal level, Allaire et al. showed EN promotes enterocyte secretion of mucin-2 protein, which maintains a mucus layer and helps flush pathogens, and resistin-like molecule- $\beta$ secretion into the submucosa, which promotes $\mathrm{CD}-4 \mathrm{~T}$ cell recruitment driving host defense mechanisms including epithelial cell proliferation [34]. EN promotes commensal bacteria to protect against enteric pathogens by (a.) direct competition for nutrients, (b.) production of antibacterial peptides, and (c.) bile salt modification rendering them harmful to other microorganisms and driving mucus production [35]. In theory, probiotics, prebiotics, or both (synbiotics) may have therapeutic value by promoting commensalism and its benefits. Fiber, an EN component, is a prebiotic for colonocyte health. Colonocytes ferment fiber into shortchain fatty acids (SCFA) butyrate, propionate, acetate, and lactic acid. SCFA has numerous benefits, such as butyrate migrating to bone marrow and stimulating effective hematopoiesis, which promotes lung protective Ly6C- and Ly6C + monocytes [36].

Davison et al. showed restoring commensal bacteria promotes differentiation of innate immune cells leading to local and distant immune modulating effects, although the optimal formulation remains under investigation [37]. Shimizu et al. demonstrated significant reduction in the enteritis and ventilator-associated pneumonia rate in septic patients receiving synbiotics [38]. These findings underscore the importance of luminal nutrients to preserve enterocyte barrier and defense functions.

\section{Is Early Enteral Nutrition in Shock Safe and Beneficial?}

Since 2017, guidelines have provided disparate recommendations, mostly pertaining to EN in septic shock. The Surviving Sepsis Campaign guideline suggests either early trophic/hypocaloric or early full EN in critically ill patients with septic shock (weak recommendation) [39]. In 2019, the European Society for Parenteral and Enteral Nutrition (ESPEN) guideline states no evidence-based answer for EN in septic shock can be proposed as no interventional studies have been reported to date [2].

Introducing luminal nutrients increases enterocyte workload and oxygen demand. As stated earlier, shock states diminish splanchnic blood flow, potentially leading to unmet gut oxygen demand, which leaves the small bowel susceptible to ischemia. As a result, non-occlusive mesenteric ischemia (NOMI) and non-occlusive bowel necrosis (NOBN) are the gravest consequences of introducing luminal nutrients into a hypoperfused bowel with mortality rates exceeding $80 \%$. The second consequence of introducing luminal nutrients into the gut is splanchnic steal, whereby preciously low systemic oxygen delivery is "stolen" by the splanchnic circulation to increase oxygen delivery for working enterocytes [3]. As a result, systemic 
oxygen delivery may be reduced, manifesting clinically as increased vasopressor dose.

Since 2017, four observational studies (Table 2) have evaluated the safety/tolerability and changes in vasopressor associated with EN in shock [40, 41••, 42••, 43]. Merchan et al. evaluated the tolerability of EN in mechanically ventilated patients with septic shock and identified zero reports of NOMI or NOBN and no significant change in vasopressor dose [40]. Similarly, Ewy et al. found no reports of NOMI or NOBN and no significant increase in norepinephrine dose at 6,12 , or $24 \mathrm{~h}$ in mechanically ventilated patients with septic shock receiving concomitant EN [43]. Ohbe et al. compared outcomes of EN in Japanese patients with cardiogenic and obstructive shock receiving veno-arterial (VA) extracorporeal membrane support $(E C M O)$ [42•*]. None of the 220 VA-ECMO patients who received early EN (within $48 \mathrm{~h}$ of ECMO) developed NOMI or NOBN, while $1 \%$ (9/1549) of those who received delayed EN (after $48 \mathrm{~h}$ ) during VA-ECMO developed NOMI. Furthermore, early EN during VA-ECMO was associated with improved 28-day mortality, as compared to delayed EN (38\% vs. $48 \%, p=0.004$ ) [42••]. In another observational study, Ohbe et al. compared outcomes between early EN (within 48 h) and late EN (after 48 h) in mechanically ventilated patients with shock requiring low-, medium-, and high-dose norepinephrine [41••]. Using propensity score matching, 5969, 2162, and 477 were identified in the low-, medium-, and high-norepinephrine groups. Amongst all patients on norepinephrine receiving early EN, $0.2 \%$ (21/8608) developed bowel ischemia, compared to $0.3 \%(50 / 17,216)$ in the late EN group ( $p$ value non-significant). Interestingly, early $\mathrm{EN}$, as compared to late EN, in the low-dose norepinephrine group was associated with reduced 28-day mortality $(-2.9 \%$; $95 \%$ confidence interval -4.5 to $-1.3 \%$ ) [41••].

Since 2017, two large pragmatic-design RCTs with an EN intervention arm have enrolled patients in shock [44, 45•*]. NUTRIREA-2 compared early PN to EN in 2410 mechanically ventilated (mostly medical ICU) patients in shock [45**]. One-hundred percent of patients in NUTRIREA-2 had circulatory shock. Of these, $62 \%$ had septic shock [45••]. There were no differences in the primary outcome of 28-day mortality between groups. NOMI occurred in 19 of $1202(2 \%)$ of patients receiving EN and in 5 of $1208(<1 \%)$ in those receiving PN (hazard ratio $3.84,95 \%$ confidence interval $1.43-10.3, p$-value $=0.007$ ) [45••]. Bowel ischemia that occurred in NUTRIREA-2 may have been related to both EN and norepinephrine dose. Nearly 20 kilocalories per kilogram per day EN was delivered to patients receiving an average norepinephrine dose of $0.56 \mu \mathrm{g}$ per kilogram per minute. More recently, the TARGET trial randomized 3957 critically ill patients to energy-dense EN or standard of care and NOMI occurred in 1 patient $(0.05 \%)$ in the energy-dense group despite receiving a median 23 kilocalories per kilogram per day and in 1 patient $(0.05 \%)$ receiving standard EN [46]. Overall, the incidence of NOMI and NOBN is rare across large randomized controlled nutrition trials enrolling patients in shock. We recently reviewed (manuscript in press) 7 large nutrition studies published since 2011 that enrolled patients on vasopressor into an EN intervention arm [47]. We identified NOMI occurred in 36 of 12,219 $(0.3 \%)$ patients receiving EN [47].

Two recent ancillary studies from the NUTRIREA-2 trial evaluating safety and benefit of early EN in shock and one pilot RCT comparing early trophic EN to 'no EN' are worth mentioning [48-50] Nseir et al. found more abundant micro-aspiration of gastric contents in those who received early PN, as compared to early EN (36\% vs. $14 \%$, $p=0.004$ ), suggesting early EN in shock is not associated with more gastric aspiration [48]. In evaluating a mechanism for benefit of EN in shock, Piton et al. reported higher day 3 plasma citrulline concentration in those randomized to early EN, as compared to early PN, suggesting early EN in shock restored/maintained enterocyte mass and function compared to early PN [49॰]. However, in the same study, serum intestinal fatty acid binding protein (I-FABP), which transports fatty acids in the enterocyte and considered a marker of enterocyte ischemia, was elevated in the early EN group, as compared to early PN group, without overt NOMI in this cohort, raising the possibility of subclinical mesenteric ischemia with full dose EN in shock. The authors state further studies should assess whether trophic $\mathrm{EN}$ in shock is associated with lower I-FABP [49॰].

Patel et al. conducted a small pilot RCT comparing the feasibility of delivering early trophic $\mathrm{EN}(<600$ kilocalories) to 'no EN' in 31 mechanically ventilated patients with septic shock [50]. Zero patients had NOMI or NOBN, early EN was well-tolerated, a signal for improved ICU- and ventilator-free days was observed, and a trend towards reduced Candida colonization in the early EN group. Even though Candida isolation is not synonymous with infection, previous studies have suggested association between Candida and persistent inflammation and immunosuppression [51, 52].

Even though the optimal dose and timing of EN are unknown and additional research is required, current evidence suggests commencing early EN in shock is welltolerated, safe, and may be associated with improved outcomes.

\section{Conclusions and Future Insight}

Circulatory shock turns on the "gut motor," which perpetuates inflammation through loss of TJ integrity and bacterial dysbiosis, which generate dysregulated immune 
Table 2 Observational and randomized controlled studies since 2017 primarily evaluating early enteral nutrition (EN) in shock

\begin{tabular}{|c|c|c|c|c|c|}
\hline Author & Date & Study question & Safety outcome & Other outcomes & Comments \\
\hline & & Observational studies & & & \\
\hline $\begin{array}{l}\text { Merchan } \\
\text { et al. } \\
\text { [40] }\end{array}$ & 2017 & $\begin{array}{l}\text { Is early EN in septic shock } \\
\text { tolerated? }\end{array}$ & $\begin{array}{l}\text { Bowel ischemia not found } \\
\text { and overall intolerance } \\
\text { identified in } 38 \% \text {, with } \\
74 \% \text { representing } \\
\text { GRV }>250 \mathrm{~mL}\end{array}$ & $\begin{array}{l}\text { First intolerant event } \\
\text { occurred with NE dose } \\
0.14 \mu \mathrm{g} / \mathrm{kg} / \mathrm{min}\end{array}$ & $\begin{array}{l}\text { EN tolerance more likely if } \\
\text { EN started within } 48 \mathrm{~h} \\
(78 \% \text { vs. } 48 \%, p=0.015)\end{array}$ \\
\hline $\begin{array}{l}\text { Ohbe } \\
\qquad \text { et al. } \\
{[42 \bullet \bullet]}\end{array}$ & 2018 & $\begin{array}{l}\text { What are the outcomes of } \\
\text { early EN, compared to } \\
\text { late EN, in cardiogenic } \\
\text { and obstructive shock } \\
\text { patients undergoing VA- } \\
\text { ECMO? }\end{array}$ & $\begin{array}{l}\text { Bowel ischemia occurred in } \\
\text { zero patients receiving } \\
\text { early EN, compared to } \\
9 / 1549(1 \%) \text { receiving late } \\
\text { EN }\end{array}$ & $\begin{array}{l}\text { Early EN associated with } \\
\text { improved 28-day mortality }\end{array}$ & $\begin{array}{l}\text { Largest observational study } \\
\text { showing early EN in } \\
\text { circulatory shock patients } \\
\text { undergoing VA-ECMO is } \\
\text { not associated with harm } \\
\text { and may be beneficial }\end{array}$ \\
\hline $\begin{array}{l}\text { Ohbe } \\
\text { et al. } \\
{\left[41^{\bullet \bullet}\right]}\end{array}$ & 2019 & $\begin{array}{l}\text { What are outcomes in } \\
\text { mechanically ventilated } \\
\text { patients with shock } \\
\text { receiving early EN, } \\
\text { compared to late EN, } \\
\text { stratified by NE dose? }\end{array}$ & $\begin{array}{l}\text { Bowel ischemia occurred in } \\
0.2 \%(21 / 8608) \text { in early } \\
\text { EN and } 0.3 \% \\
(50 / 17,216) \text { in late EN }\end{array}$ & $\begin{array}{l}\text { Early EN associated with } \\
\text { lower } 28 \text {-day mortality in } \\
\text { low dose }(-2.9 \%, \mathrm{CI} \\
-4.5 \% \text { to }-1.3 \%) \text { and } \\
\text { medium dose }(-6.8 \%, \mathrm{CI} \\
-9.6 \% \text { to } 4.0 \%) \mathrm{NE} \\
\text { groups }^{\mathrm{a}}\end{array}$ & $\begin{array}{l}\text { Largest observational study } \\
\text { evaluating the impact of } \\
\text { early versus late EN in } \\
\text { patients with shock, as } \\
\text { stratified by NE dose }\end{array}$ \\
\hline \multirow[t]{2}{*}{$\begin{array}{l}\text { Ewy } \\
\text { et al. } \\
\text { [43] }\end{array}$} & 2019 & $\begin{array}{l}\text { In patients with septic } \\
\text { shock, does NE dose } \\
\text { increase in the } \\
\text { subsequent } 6,12 \text {, and } \\
24 \mathrm{~h} \text { after commencing } \\
\text { EN? }\end{array}$ & $\begin{array}{l}\text { No reports of NOMI or } \\
\text { NOBN }\end{array}$ & $\begin{array}{l}\text { No significant change in NE } \\
\text { dose in } 31 \text { mechanically } \\
\text { ventilated patients with } \\
\text { septic shock receiving } \\
\text { concomitant EN }\end{array}$ & $\begin{array}{l}\text { This study suggests } \\
\text { delivering EN in patients } \\
\text { with septic shock is not } \\
\text { associated with an increase } \\
\text { in NE dose, which } \\
\text { challenges the splanchnic } \\
\text { steal phenomenon }\end{array}$ \\
\hline & & Randomized controlled trials & & & \\
\hline $\begin{array}{l}\text { Reignier } \\
\text { et al. } \\
{\left[45^{\bullet \bullet}\right]}\end{array}$ & 2018 & $\begin{array}{l}\text { In mechanically ventilated } \\
\text { adults with shock, does } \\
\text { early PN, compared to } \\
\text { early EN, improve } \\
\text { 28-day mortality? }\end{array}$ & $\begin{array}{l}\text { Bowel ischemia occurred in } \\
2 \% \text { in early EN, as } \\
\text { compared to }<1 \% \text { in early } \\
\text { PN ( } p=0.007) \text {. Vomiting } \\
\text { occurred in } 34 \% \text { in early } \\
\text { EN, compared to } 24 \% \text { in } \\
\text { early PN }(p<0.0001)\end{array}$ & $\begin{array}{l}\text { No difference in primary } \\
\text { outcome of } 28 \text {-day } \\
\text { mortality ( } 37 \text { vs. } 35 \% \text {, } \\
p=0.33 \text { ) }\end{array}$ & $\begin{array}{l}\text { Early EN patient received } \\
\text { mean } 17.8 \mathrm{kcal} / \mathrm{kg} / \text { day } \\
\text { while on mean NE dose of } \\
0.56 \mu \mathrm{g} / \mathrm{kg} / \mathrm{min} \text {, which } \\
\text { may have accounted for the } \\
\text { NOBN observed in this } \\
\text { group }\end{array}$ \\
\hline $\begin{array}{l}\text { Patel } \\
\text { et al. } \\
{[50]}\end{array}$ & 2019 & $\begin{array}{l}\text { In mechanically ventilated } \\
\text { adults with septic shock, } \\
\text { is delivering trophic EN, } \\
\text { compared to 'no EN,' } \\
\text { feasible? }\end{array}$ & $\begin{array}{l}\text { No patient developed NOMI } \\
\text { or NOBN }\end{array}$ & $\begin{array}{l}\text { Signals for improved ICU } \\
\text { and ventilator-free days in } \\
\text { this pilot study }\end{array}$ & $\begin{array}{l}\text { Early trophic EN group had } \\
\text { less subsequent cultures } \\
\text { growing Candida, } \\
\text { compared to 'no EN, } \\
\text { suggesting a beneficial role } \\
\text { of early trophic EN in } \\
\text { maintaining gut integrity }\end{array}$ \\
\hline
\end{tabular}

$V A-E C M O$ veno-arterial extracorporeal membrane oxygenation, $G R V$ gastric residual volume, $m L$ milliliters, $I C U$ intensive care unit, $N O B N$ non-occlusive bowel necrosis, NOMI non-occlusive mesenteric ischemia, $P N$ parenteral nutrition

${ }^{\mathrm{a}}$ Low dose norepinephrine (NE) defined as $<0.1 \mu \mathrm{g} / \mathrm{kg} / \mathrm{min}$ and medium dose as $0.1-0.3 \mu \mathrm{g} / \mathrm{kg} / \mathrm{min}$

responses. Early EN, as a form of therapy, may maintain enterocyte barrier function and provide substrate for bacteria to limit dysbiosis to prevent dysregulated immune responses. Recent observational and RCT data show early EN is well-tolerated and safe whereby the incidence of NOMI and NOBN is low. Furthermore, emerging observational and pilot RCT data suggest benefit from early EN in shock. The only large RCT comparing EN in shock had $\mathrm{PN}$ as a comparator group. Large-scale RCTs comparing different EN doses in circulatory shock are lacking. Future research testing the role of EN in shock is needed to identify optimal EN timing, dose, and composition.

\section{Compliance with Ethical Guidelines}

Conflicts of interest The authors have no potential conflicts of interest to declare.

Human and Animal Rights and Informed Consent This article does not contain any studies with human or animal subjects performed by any of the authors. 


\section{References}

Papers of particular interest, published recently, have been highlighted as:

- Of importance

-• Of major importance

1. Cuthbertson BH. Post-shock metabolic response. Lancet. 1942;239:433-7.

2. Singer P, Blaser AR, Berger MM, et al. ESPEN guideline on clinical nutrition in the intensive care unit. Clin Nutr. 2019;38(1):48-79.

3. Cresci G, Cue J. The patient with circulatory shock: to feed or not to feed? Nutr. Clin. Pract. 2008;23(5):501-9.

4. - Arabi YM, McClave SA. Enteral nutrition should not be given to patients on vasopressor agents. Crit Care Med. 2018. This is an excellent approach to delivering enteral nutrition in critically ill patients on vasopressor support.

5. - Vermette D, Hu P, Canarie MF, Funaro M, Glover J, Pierce RW. Tight junction structure, function, and assessment in the critically ill: a systematic review. Intensive Care Med. Exp. 2018;6(1):37. This is a systematic review of studies evaluating enterocyte tight junction in critically ill patients.

6. Lorentz CA, Liang Z, Meng M, et al. Myosin light chain kinase knockout improves gut barrier function and confers a survival advantage in polymicrobial sepsis. Mol Med. 2017;23:155-65.

7. - McClave SA, Lowen CC, Martindale RG. The 2016 ESPEN Arvid Wretlind lecture: The gut in stress. Clin Nutr. 2018;37(1):19-36. This is a detailed review of the mechanisms of gut dysfunction in critical illness.

8. Yoseph BP, Klingensmith NJ, Liang Z, et al. Mechanisms of intestinal barrier dysfunction in sepsis. Shock. 2016;46(1):52-9.

9. Angarita SAK, Duarte S, Russell TA, et al. Quantitative measure of intestinal permeability using blue food coloring. J Surg Res. 2019;233:20-5.

10. Powell N, MacDonald TT. Recent advances in gut immunology. Parasite Immunol. 2017;39(6):12430.

11. Lu JT, Xu AT, Shen J, Ran ZH. Crosstalk between intestinal epithelial cell and adaptive immune cell in intestinal mucosal immunity. J Gastroenterol Hepatol. 2017;32(5):975-80.

12. Greis C, Rasuly Z, Janosi RA, Kordelas L, Beelen DW, Liebregts $\mathrm{T}$. Intestinal $\mathrm{T}$ lymphocyte homing is associated with gastric emptying and epithelial barrier function in critically ill: a prospective observational study. Crit Care. 2017;21(1):70.

13. Brakenridge SC, Moore FA, Mercier NR, et al. Persistently elevated glucagon-like peptide-1 levels among critically Ill surgical patients after sepsis and development of chronic critical illness and dismal long-term outcomes. J Am Coll Surg. 2019;229:58-67.

14. - Dickson RP. The microbiome and critical illness. Lancet Respir Med. 2016;4(1):59-72. This is an excellent review of critical illness pathophysiology and intensive care unit intervention related mechanisms that contribute to dysbiosis during critical illness.

15. •• McDonald D, Ackermann G, Khailova L, et al. Extreme dysbiosis of the microbiome in critical illness. mSphere. 2016;1(4):e00199-16. This is the largest gut microbiota study in critically ill patients. The study compared critical illness gut microbiota to healthy microbiota composition and demonstrated a shift towards pathogenic bacteria during critical illness.

16. Lankelma JM, van Vught LA, Belzer C, et al. Critically ill patients demonstrate large interpersonal variation in intestinal microbiota dysregulation: a pilot study. Intensive Care Med. 2017;43(1):59-68.
17. Krezalek MA, DeFazio J, Zaborina O, Zaborin A, Alverdy JC. The shift of an intestinal "Microbiome" to a "Pathobiome" governs the course and outcome of sepsis following surgical injury. Shock. 2016;45(5):475-82.

18. •- Alverdy JC, Krezalek MA. Collapse of the microbiome, emergence of the pathobiome, and the immunopathology of sepsis. Crit Care Med. 2017;45(2):337-347. This is an excellent overview of how the (gut) microbiome shifts to a pathobiome in critical illness.

19. Babrowski T, Romanowski K, Fink D, et al. The intestinal environment of surgical injury transforms Pseudomonas aeruginosa into a discrete hypervirulent morphotype capable of causing lethal peritonitis. Surgery. 2013;153(1):36-43.

20. Lamarche D, Johnstone J, Zytaruk N, et al. Microbial dysbiosis and mortality during mechanical ventilation: a prospective observational study. Respir Res. 2018;19(1):245.

21. Bajaj JS, Vargas HE, Reddy KR, et al. Association between intestinal microbiota collected at hospital admission and outcomes of patients with cirrhosis. Clin Gastroenterol Hepatol. 2019;17(4):756-765 e753.

22. Dickson RP, Singer BH, Newstead MW, et al. Enrichment of the lung microbiome with gut bacteria in sepsis and the acute respiratory distress syndrome. Nat Microbiol. 2016;1(10):16113.

23. Kojima M, Gimenes-Junior JA, Chan TW, et al. Exosomes in postshock mesenteric lymph are key mediators of acute lung injury triggering the macrophage activation via Toll-like receptor 4. FASEB J. 2018;32(1):97-110.

24. Yamada T, Shimizu K, Ogura H, et al. Rapid and sustained longterm decrease of fecal short-chain fatty acids in critically Ill patients with systemic inflammatory response syndrome. JPEN J Parenter Enter Nutr. 2015;39(5):569-77.

25. Ojima M, Motooka D, Shimizu K, et al. Metagenomic analysis reveals dynamic changes of whole gut microbiota in the acute phase of intensive care unit patients. Dig Dis Sci. 2016;61(6):1628-34.

26. Bhalodi AA, van Engelen TSR, Virk HS, Wiersinga WJ. Impact of antimicrobial therapy on the gut microbiome. J Antimicrob Chemother. 2019;74(Supplement_1):i6-15.

27. Harvey SE, Segaran E, Leonard R. Trial of the route of early nutritional support in critically ill adults. $\mathrm{N}$ Engl $\mathrm{J}$ Med. 2015;372(5):488-9.

28. Demehri FR, Barrett M, Teitelbaum DH. Changes to the intestinal microbiome with parenteral nutrition: review of a murine model and potential clinical implications. Nutr Clin Pract. 2015;30(6):798-806.

29. Alverdy J, Gilbert J, DeFazio JR, et al. Proceedings of the 2013 A.S.P.E.N. Research workshop: the interface between nutrition and the gut microbiome: implications and applications for human health [corrected]. JPEN J Parenter Enter Nutr. 2014;38(2):167-78.

30. Feng Y, Barrett M, Hou Y, Yoon HK, Ochi T, Teitelbaum DH. Homeostasis alteration within small intestinal mucosa after acute enteral refeeding in total parenteral nutrition mouse model. Am J Physiol Gastrointest Liver Physiol. 2016;310(4):G273-84.

31. Barrett M, Demehri FR, Teitelbaum DH. Intestine, immunity, and parenteral nutrition in an era of preferred enteral feeding. Curr Opin Clin Nutr Metab Care. 2015;18(5):496-500.

32. Freeman JJ, Feng Y, Demehri FR, Dempsey PJ, Teitelbaum DH. TPN-associated intestinal epithelial cell atrophy is modulated by TLR4/EGF signaling pathways. FASEB J. 2015;29(7):2943-58.

33. Ralls MW, Demehri FR, Feng Y, Woods Ignatoski KM, Teitelbaum DH. Enteral nutrient deprivation in patients leads to a loss of intestinal epithelial barrier function. Surgery. 2015;157(4):732-42.

34. Allaire JM, Morampudi V, Crowley SM, et al. Frontline defenders: goblet cell mediators dictate host-microbe interactions 
in the intestinal tract during health and disease. Am J Physiol Gastrointest Liver Physiol. 2018;314(3):G360-77.

35. Haak BW, Prescott HC, Wiersinga WJ. Therapeutic potential of the gut microbiota in the prevention and treatment of sepsis. Front Immunol. 2018;9:2042.

36. Dang AT, Marsland BJ. Microbes, metabolites, and the gut-lung axis. Mucosal Immunol. 2019;12:843-50.

37. Davison JM, Wischmeyer PE. Probiotic and synbiotic therapy in the critically ill: state of the art. Nutrition. 2019;59:29-36.

38. Shimizu K, Yamada T, Ogura H, et al. Synbiotics modulate gut microbiota and reduce enteritis and ventilator-associated pneumonia in patients with sepsis: a randomized controlled trial. Crit Care. 2018;22(1):239.

39. Rhodes A, Evans LE, Alhazzani W, et al. Surviving sepsis campaign: international guidelines for management of sepsis and septic shock: 2016. Intensive Care Med. 2017;43(3):304-77.

40. Merchan C, Altshuler D, Aberle C, Papadopoulos J, Schwartz D. Tolerability of enteral nutrition in mechanically ventilated patients with septic shock who require vasopressors. J Intensive Care Med. 2017;32(9):540-6.

41. • Ohbe H, Jo T, Matsui H, Fushimi K, Yasunaga H. Differences in effect of early enteral nutrition on mortality among ventilated adults with shock requiring low-, medium-, and high-dose noradrenaline: a propensity-matched analysis. Clin Nutr. 2019. This is the largest observational study evaluating early enteral nutrition in circulatory shock.

42. • Ohbe H, Jo T, Yamana H, Matsui H, Fushimi K, Yasunaga H. Early enteral nutrition for cardiogenic or obstructive shock requiring venoarterial extracorporeal membrane oxygenation: a nationwide inpatient database study. Intensive Care Med. 2018;44(8):1258-65. This is the largest observational study evaluating early enteral nutrition in circuatory shock patients receiving veno-arterial extracorporeal membrane oxygenation.

43. Ewy M, Aqeel M, Kozeniecki M, et al. The impact of enteral feeding on vasoactive support in septic shock: a retrospective observational study. Aspen nutrition science and practice conference: Phoenix, Arizona, March 23-26, 2019. J Parenter Enter Nutr. 2019;43:445. https://doi.org/10.1002/jpen.1511.

44. Chapman M, Peake SL, Bellomo R, et al. Energy-dense versus routine enteral nutrition in the critically Ill. N Engl J Med. 2018;379(19):1823-34.
45. •• Reignier J, Boisrame-Helms J, Brisard L, et al. Enteral versus parenteral early nutrition in ventilated adults with shock: a randomised, controlled, multicentre, open-label, parallel-group study (NUTRIREA-2). Lancet. 2018;391(10116):133-43. This is the largest randomized controlled trial evaluating the role of early enteral nutrition (compared to early parenteral nutrition) in mechanically ventilated patients with circulatory shock.

46. Peake SL, Chapman MJ, Investigators T. Energy-dense versus routine enteral nutrition in the critically Ill. N Engl J Med. 2019;380(5):499-500.

47. Patel JJ, Heyland DK, Rice TW. Enteral nutrition in shock: less may be more. Crit Care. 2019;47:e794-5 in press.

48. Nseir S, Le Gouge A, Lascarrou JB, et al. Impact of nutrition route on microaspiration in critically ill patients with shock: a planned ancillary study of the NUTRIREA-2 trial. Crit Care. 2019;23(1):111.

49. - Piton G, Le Gouge A, Brule N, et al. Impact of the route of nutrition on gut mucosa in ventilated adults with shock: an ancillary of the NUTRIREA-2 trial. Intensive Care Med. 2019. This is a NUTRIREA-2 substudy that shows the luminal benefits of early enteral nutrition, as determined by serum citrulline and fatty acid binding protein.

50. Patel JJ, Kozeniecki M, Peppard WJ, Peppard SR, Zellner-Jones S, Graf J, Szabo A, Heyland D. A phase III pilot randomized controlled trial comparing early trophic enteral nutrition to 'No Enteral Nutrition' in mechanically ventilated patients with septic shock. American society of parenteral and enteral nutrition 2019 nutrition science and practice conference, 2019, Phoenix, Arizona.

51. Delisle MS, Williamson DR, Albert M, et al. Impact of Candida species on clinical outcomes in patients with suspected ventilatorassociated pneumonia. Can Respir J. 2011;18(3):131-6.

52. Albert M, Williamson D, Muscedere J, et al. Candida in the respiratory tract secretions of critically ill patients and the impact of antifungal treatment: a randomized placebo controlled pilot trial (CANTREAT study). Intensive Care Med. 2014;40(9):1313-22.

Publisher's Note Springer Nature remains neutral with regard to jurisdictional claims in published maps and institutional affiliations. 